\title{
GEORREFERÊNCIA E HOMOSSOCIABILIDADE: UM ESTUDO NA REGIÃO DE CONFRESA - MT (2020)
}

\author{
GEORREFERENCE AND HOMOSOCIABILITY: A STUDY IN CONFRESA'S \\ SURROUNDINGS (2020)
}

\author{
Rogério Makino \\ Doutor em Ciências Sociais/Universidade de Brasília \\ Professor Substituto da UNEMAT/Campus Tangará da Serra \\ E-mail: makinotga@gmail.com
}

\author{
Hérica Makino \\ Doutoranda pelo PPG-VET/UFMT \\ Servidora Pública da UFMT/Campus Cuiabá \\ E-mail: hericamak@yahoo.com.br
}

\begin{abstract}
Resumo: O mundo virtual e os aplicativos de namoros aumentaram a possibilidade de encontrar parceiros afetivos-sexuais, especialmente entre minorias. $\mathrm{O}$ objetivo dessa pesquisa é descrever a homossociabilidade no mundo virtual dos usuários da região de Confresa - MT. Os dados dos usuários desse e de outros municípios mato-grossenses foram coletados a partir de um aplicativo de namoro, o Grindr, entre janeiro e fevereiro de 2020. Entre os resultados mais significativos, foi identificado que o número de usuários nessa região é extremamente baixo e uma parte dele é constituída de transeuntes, ou seja, a homossociabidade de residentes da região pelo aplicativo não é um fenômeno significativo do ponto de vista quantitativo, comparado a outras cidades de Mato Grosso. A maioria dos usuários evita expor o rosto, o que sugere um ambiente muito heteronormativado. Ninguém assumiu uma sorologia positiva nos 100 perfis mais próximos, embora estatisticamente seja provável que haja soropositivos nesse grupo social.
\end{abstract}

Palavras-chave: Confresa - MT; Grindr; heteronormatividade; minorias sexuais;

\begin{abstract}
The virtual world and the date apps increased the possibility of finding partners, especially for sexual minorities. This research aims to describe homosociability in the virtual world of the users from Confresa's surroundings. The data of Grindr users in Confresa and other cities in Mato Grosso was collected during January and February of 2020. Among the most important results, we identified that the number of users in this region is extremely low and some of them are just travellers, that is, homosociability in the virtual world is not a significative phenomenon in this region in quantitative terms, in comparison of others areas in Mato Grosso. Most of the users avoids exposing their faces, which indicates a very heteronormativated enviroment. No one has admitted being HIV positive in 100 profiles nearby; but statistically this completely absence of HIV positive is little probable.
\end{abstract}

Key words: Confresa - Brazil; Grindr; heteronormativity; sexual minorities; 


\section{Introdução}

A internet significou uma mudança paradigmática na forma em que pessoas não heterossexuais ${ }^{1}$ buscam se relacionar afetiva e sexualmente. A invenção dos smartphones e dos aplicativos de namoro significaram um aprofundamento nesse paradigma. Conforme expõem Blackwell et al. (2015), antes da internet, eram muitas as limitações para um homossexual ou bissexual masculino para encontrar um parceiro: a dificuldade de discernir a orientação sexual de homens não afeminados, o medo de sofrer violência física ou preconceito, a dificuldade de encontrar pessoas compatíveis com sua preferência sexual (ativo, versátil ou passivo), etc. ${ }^{2}$ Os aplicativos de paquera dos smartphones permitiram que pessoas com desejos compatíveis pudessem se encontrar, significando uma ampliação da possibilidade de relacionamentos.

O objetivo desse artigo é descrever algumas das características da homossociabilidade na região de Confresa - MT, a partir de informações coletadas a partir do Grindr - aplicativo de paquera e namoro mais popular entre homens não heterossexuais, de acordo com o número de downloads no GooglePlay em smartphones que usam sistema operacional android. Entre as características estudadas estão as dos próprios usuários (soropositividade, exposição do rosto, idade, etc.), as dos quantitativos e de distribuição de usuários pela região de Confresa e as da localização dos usuários. Trata-se de uma pesquisa descritiva, ou seja, que relata as características do objeto estudado, sem ter como pretensão principal o estabelecimento de relação causal (GIL, 1999).

Os instrumentos de coleta de dados utilizados foram o aplicativo Grindr e o aplicativo Fake Location. Esse último permite fazer com que o sistema operacional do smartphone simule uma localização virtual (falsa) indicada pelo usuário como se fosse a localização real. Isso permite investigar várias localidades sem ter a necessidade de se deslocar até elas.

Os dados foram coletados em entre 27 janeiro de 2020 e 1 de fevereiro de 2020. A análise dos dados foi feita por meio da tabulação dos números obtidos, que foram comparados sincronicamente com o de outras regiões e diacronicamente ao longo de períodos descritos. Além disso, algumas interpretações sobre os números foram apontadas.

\footnotetext{
1 A terminologia usada em relação às minorias sexuais tem mudado muito nas últimas décadas. A própria comunidade dessas minorias já foi chamada de GLS, LGBT, LGBTS, LGBTTS, LGBTTQI+, etc. O termo "não heterossexual", que pode ser considerado impróprio em algumas perspectivas teóricas, aqui se refere a todos aqueles que fogem aos padrões heteronormativos.

2 Essa dificuldade dos relacionamentos não heterossexuais é relatada, por exemplo, em uma parte do livro Outsiders, de Howard Becker, um clássico da Sociologia.
} 


\section{Heteronormatividade e Homossociabilidade}

O termo heteronormatividade (heterossexismo ou heterocentrismo) é utilizado na área multidisciplinar dos estudos de gênero para se referir à naturalização da heterossexualidade cissexual como a única forma legítima de estabelecer relações afetivo-sexuais entre dois seres humanos, de modo que outras combinações são consideradas abjetas ou abominações. Em outras palavras, a heterossexualidade é apresentada como normal ou natural, construindo-se mecanismos sociais coercitivos ou punitivos para tentativas de desvios desse padrão.

[A heteronormatividade] é um conjunto de prescrições que fundamenta processos sociais de regulação e controle, até mesmo aqueles que não se relacionam com pessoas do sexo oposto. Assim, ela não se refere apenas aos sujeitos legítimos e normalizados, mas é a denominação contemporânea para o dispositivo histórico da sexualidade que evidencia seu objeto: formar todos para serem heterossexuais ou organizarem suas vidas a partir do modelo supostamente coerente, superior e "natural" da heterossexualidade. (MISKOLCI, 2009, p. 157).

O termo heteronormatividade, usado pela primeira vez por Michael Warner (1991), acabou se popularizando mais do que outros que expressavam ideias afins como a de "heterossexualidade compulsória" usado por Rich em 1990 (RICH, 2004) ou "matriz heterossexual" de Butler (1990). Entre os elementos comuns a heteronormatividade estão as manifestações de natureza homofóbica, lesbofóbica ou transfóbica que podem variar desde a violência simbólica até a violência física. Algumas instituições sociais como igrejas costumam ser muito resistentes a mudanças nos valores heteronormativos e algumas explicações biologicistas simplistas do senso comum que giram em torno do argumento reprodutivo costumam ser extremamente persuasivas e difíceis de serem desconstruídas.

Em uma lógica desviante à heteronormatividade, há a homossociabilidade. Esse é um termo usado de forma não muito precisa, aparecendo em diferentes trabalhos com algumas variações de sentido. Em Rios (2008), por exemplo, essa palavra aparece no sentido de interação entre pessoas de orientação sexual não heterossexual, associado à busca de prazer (implicitamente prazer sexual). Já em Lazarini e Rial (2010), a homossociabilidade enfatiza mais a possibilidade de ir a lugares frequentados por não heterossexuais, sem que a orientação sexual represente um problema. Nesse trabalho, a homossociabilidade é entendida como a busca pela interação com pessoas de orientações sexuais não heteronormativadas, em termos de coleguismo, de amizade e/ou de natureza afetivo-sexual.

No passado, os espaços de homossociabilidade eram mais restritos que atualmente, como atestam eventos como o de Stonewall em 1969, considerado o primeiro protesto, rebelião 
ou manifestação gay ${ }^{3}$ (COLLIN, 2011). A maior parte dos redutos de homossociabilidade era bares ou casas noturnas em algumas metrópoles, povoando o imaginário coletivo como um lugar de desviantes ou frequentado pela excrescência da sociedade.

Os aplicativos de namoro para o público gay acabaram por se tornar lugares virtuais de homossociabilidade, facilitando encontros, trocas de informações e aproximação de pessoas que não se sentem confortáveis em frequentar bares e boates gays. Em outras palavras, eles possibilitaram a homossociabilidade mesmo em cidades pequenas com sociedades conservadoras.

\subsection{Os Aplicativos de Namoro por Georreferência}

A partir dos anos 2000s, vários smartphones passaram a ter um sensor de GPS (Global Position System ou Sistema de Posicionamento Global), um sistema de localização na qual o sensor em comunicação com o satélite permite identificar com precisão a localização do aparelho. Não tardou para que a lógica do GPS fosse incorporada aos aplicativos de namoro para que esses encontrassem os candidatos a parceiros geograficamente mais próximos. Um exemplo famoso é o aplicativo Tinder que já foi baixado, instalado e usado por milhões de pessoas mundo afora (TANNUS, 2018).

Alguns aplicativos tiveram como alvos públicos mais específicos, como para lésbicas ou gays masculinos. E, mesmo dentro desses públicos, há ainda outros subgrupos, como para determinados fenótipos ou com fetiches muito particulares, como sadomasoquistas. De um modo geral, os aplicativos voltados para o público masculino homossexual e bissexual ${ }^{4}$ mais conhecidos são o Grindr, o Hornet e o Scruff. O primeiro foi o analisado nesse estudo.

O Grindr foi criado em 2009 e tinha mais de 10 milhões de downloads de acordo com o GooglePlay em fevereiro de 2020. Como comentam Brubaker et al (2016), o aumento de usuários nos últimos anos está diretamente relacionado com o aumento da popularidade dos smartphones e do maior acesso a internet móvel. Nele, o usuário pode apresentar o perfil, colocando um nome (que pode ser o nome verdadeiro ou um nome fictício), descrevendo suas características físicas e de personalidade, também sendo possível colocar um pequeno álbum

\footnotetext{
3 Stonewall era um bar de Nova Iorque frequentado por homossexuais masculinos, mas que era alvo da arbitrariedade da polícia.

4 A terminologia mais contemporânea evita palavras como "homossexual", "bissexual" ou "não heterossexual", por considerar que elas categorizam, rotulam, cristalizam e essencializam seres socialmente construídos e capazes de se desconstruir. O termo mais utilizado é "homens que fazem sexo com homens". Mesmo assim, nesse trabalho, optamos por utilizar ocasionalmente aquelas palavras.
} 
de fotos. Mas a foto de rosto não é obrigatória nem as outras informações mencionadas. Alguns usuários colocam fotos de seus rostos e informações reais, outros omitem e outros criam perfis falsos. De acordo com Blackwell et al. (2015), quanto mais homofóbica e heteronormativada é uma cidade tanto menos os usuários mostram seus rostos no perfil público.

O Grindr tem duas versões, uma gratuita e outra paga. Na primeira, o usuário pode ver até 100 perfis dos usuários mais próximos. Em lugares como o centro de Cuiabá, os 100 usuários mais próximos estão em um raio de $1 \mathrm{~km}$ de distância, enquanto em outros como Confresa, eles estão distribuídos em um raio de mais de $300 \mathrm{kms}$, alcançando perfis até a cidade de Palmas - TO, dependendo do horário. Na versão paga, o usuário pode interagir até com os 600 perfis mais próximos e tem uma série de outros recursos, como filtros de usuários por idade, raça, altura, status sorológico (portador ou não de HIV), etc. O Grindr tem por opção padrão mostrar a distância dos usuários, embora eles possam ocultar essa informação se desejarem, mas que ainda pode ser estimada sem uma precisão exata. Essa lógica georreferencial facilita que o encontro virtual passe a ser um encontro real.

Desde a sua criação, o Grindr tem chamado a atenção de pesquisadores das mais variadas áreas e temáticas - Sociologia, Psicologia, Antropologia, Comunicação, etc. - e a publicação de pesquisas, sobretudo em língua inglesa, tem sido imensa. Exemplos de pesquisas são as de Blackwell et al (2015), sobre como as pessoas querem ver e serem vistas nesse aplicativo, e as de Brubaker et al (2016) sobre o porquê de alguns usuários abandonarem o aplicativo.

Contudo, um dos temas que tem chamado mais atenção é sobre o impulso dado pelo Grindr e aplicativos similares ao aumento da disseminação do vírus HIV entre homens que transam com homens, como na pesquisa de Rice et al (2012).

\subsection{Confresa e os Usuários do Grindr}

Confresa é uma cidade cerca de 30 mil habitantes (IBGE, 2018), a maior do nordeste de Mato Grosso, região situada entre a Reserva do Xingu e o Vale do Rio Araguaia, a cerca de 100 km da divisa com Tocantins (MORENO \& HIGA, 2017, p. 73). De acordo com os dados coletados, no horário de pico do uso do Grindr, entre 19:00 e 23:00, o número de usuários em Confresa chegou a 14 usuários no período estudado, sendo uma grande parte de pessoas de passagem pela cidade, geralmente a trabalho. Essa última informação é interessante porque indica que há poucos usuários-moradores da cidade, ou seja, uma baixa popularidade do aplicativo entre os confresenses, mas que as pessoas que estão em viagem costumam buscar 
sexo casual. Como há poucos usuários do aplicativo em Confresa e cidades circunvizinhas, para se apresentar os cem usuários mais próximos, o aplicativo chega a apresentar perfis de Gurupi - TO, a 290 quilômetros em linha reta distante de Confresa.

A seguir mostramos na figura 1 a Área Alcançada pelo Grindr tendo como referência a cidade de Confresa - MT.

\section{Figura 1 - Área Alcançada pelo Grindr}

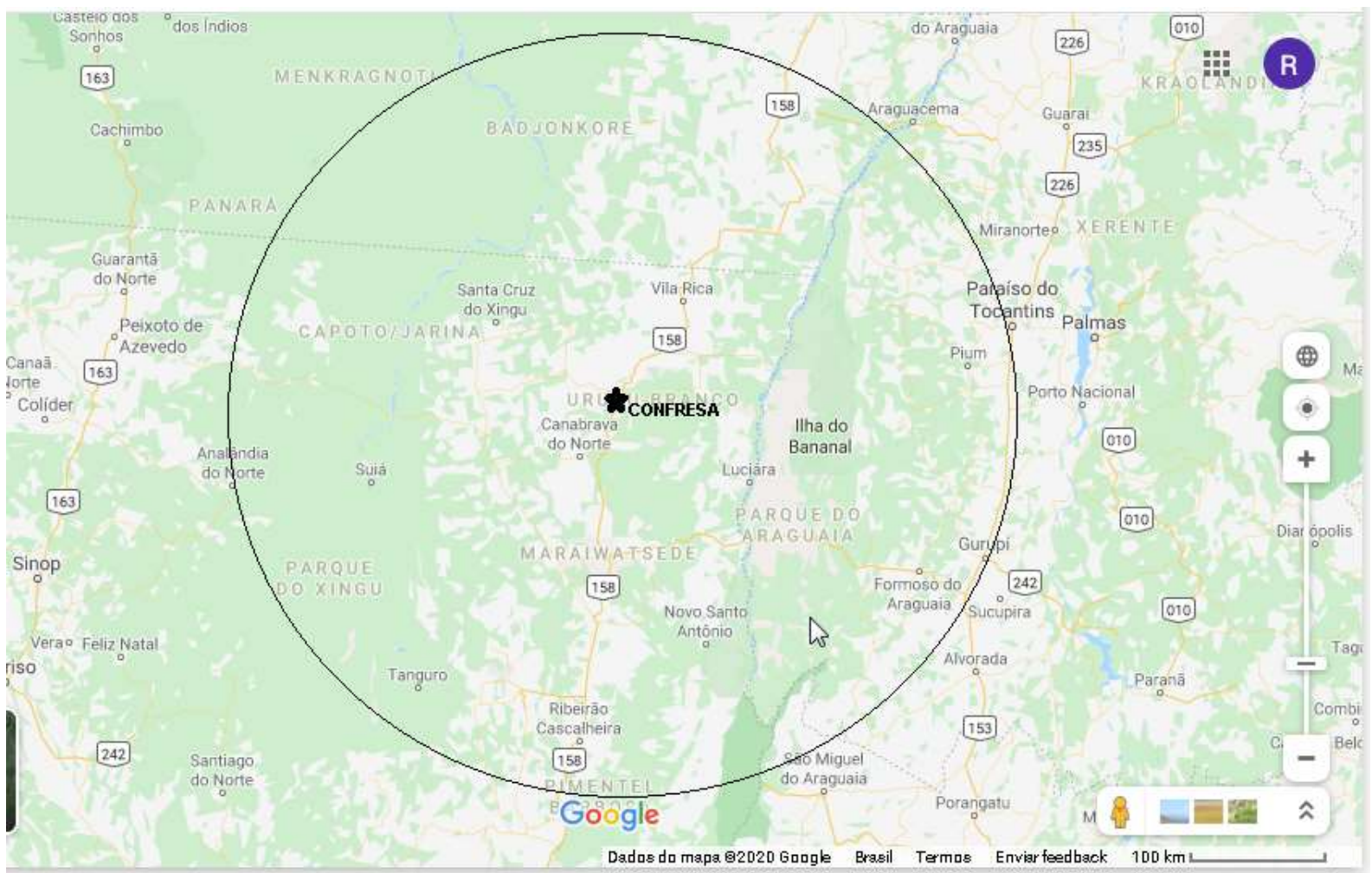

Fonte: Elaborado pelos Autores com o Google Maps.

O número de usuários que aparecem no aplicativo (“online” e "online há menos de uma hora") varia muito ao longo do dia. O horário mais movimentado em Confresa é após as 19:00 e antes das 23:00 e o menos movimentado é de madrugada, quando chega a zerar, conforme é demonstrado no Gráfico 1. Esse padrão é similar ao observado nas experiências feitas em relação aos outros municípios pesquisados.

Gráfico 1 - Variação no número de usuários online ao longo do dia em Confresa - MT 


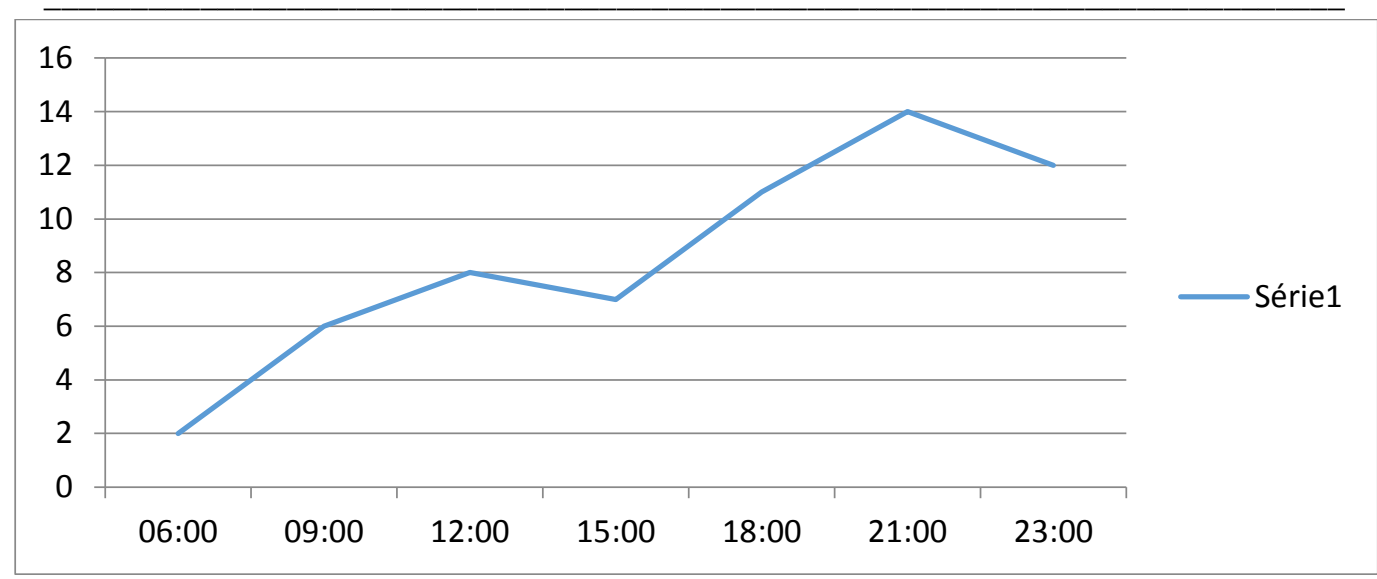

Fonte: Elaborado pelos autores

$\mathrm{Na}$ realidade, em toda a região nordeste do Araguaia - somando-se mais de dez municípios, o aplicativo não tem muitos usuários, o que indica uma homossociabilidade virtual muito baixa na região. Isso pode ocorrer em função: (1) do desconhecimento da existência desse tipo de aplicativo; (2) das pressões sociais heteronormativas e o medo de ter sua orientação descoberta; (3) baixo acesso a smartphones compatíveis com o aplicativo e ausência de internet suficientemente boa para o uso do aplicativo; (4) alguma especificidade do mês de janeiro, como as pessoas terem saído de férias da cidade. Não foi possível testar as hipóteses acima, mas elas não são mutuamente excludentes; são complementares. O baixo número absoluto e relativo de usuários pode ser observado nas tabelas 1 e 2 , respectivamente:

\section{Tabela 1 - Usuários no horário de pico nas cidades próximas a Confresa}

Cidade

Distância de Confresa População
em linha Reta

Usuários $^{5}$

IBGE 2018

Confresa

Porto Alegre do Norte

$26 \mathrm{kms}$

Canabrava do Norte

$52 \mathrm{kms}$

Vila Rica

$86 \mathrm{kms}$

25.570

6

Santa Cruz do Xingu

$106 \mathrm{kms}$

2.495

não

identificado $^{6}$

5 Número aproximado em função da possibilidade da função de omitir a localização do aplicativo. Em alguns casos, quando foi omitida a localização, fez-se uso do messenger do Grindr para perguntar a localização, mas nem sempre a resposta foi obtida.

6 Como os usuários podem omitir a sua localização, em cidades muito pequenas eles preferem fazê lo. Pode ser que houvesse usuários nessas cidades, mas não foi possível identificar. 


$\begin{array}{lccc}\text { Alto Boa Vista } & 114 \mathrm{kms} & 6.659 & \begin{array}{r}\text { não } \\ \text { identificado }\end{array} \\ \begin{array}{l}\text { Luciara } \\ 116 \mathrm{kms}\end{array} & 2.099 & \begin{array}{r}\text { não } \\ \text { identificado }\end{array} \\ \begin{array}{l}\text { Santa Terezinha } \\ \text { São Jose do Xingu }\end{array} & 8.281 & \begin{array}{r}\text { não } \\ \text { identificado }\end{array} \\ \text { São Félix do Araguaia } & 118 \mathrm{kms} & 5.569 & \begin{array}{c}\text { não } \\ \text { identificado }\end{array} \\ & 143 \mathrm{kms} & 11.615 & 1\end{array}$

Tabela 2 - Usuários online do grindr nos horários de pico em algumas cidades matogrossenses

Cidade

População (IBGE 2018)

Usuários
Cuiabá e Várzea Grande ${ }^{7}$
Rondonópolis
Sinop

Tangará da Serra

Cáceres

Sorriso

Lucas do Rio Verde

Primavera do Leste

Barra do Garças ${ }^{8}$
889.162

228.857

139.935

101.764

93.882

87.815

63.411

61.038

60.661 mais de 600

mais de 100

mais de 100

68

45

37

72

39

59

Fonte: Elaborado pelos Autores

Note-se que mesmo que se considere toda a circunvizinhança de Confresa (raio de 143 kms), uma região com mais de 80 mil habitantes, o número de usuários do aplicativo (menos de 30 pessoas) ainda é menor do que o das cidades mato-grossenses mais populosas. É uma

\footnotetext{
7 Não é possível distinguir os usuários de aglomerados urbanos como Cuiabá e Várzea Grande ou de Barra do Garças e cidades adjacentes.

8 Barra do Garças - MT forma uma conurbação junto às cidades de Pontal do Araguaia - MT (cerca de 6 mil habitantes) e Aragarças - GO (cerca de 17 mil habitantes). O número de usuários refere-se ao total desse aglomerado de cidades.
} 
região de pouco uso do aplicativo, que atualmente é o meio mais rápido e prático de homossociabilidade. Complementarmente, foram feitas experiências com outros aplicativos (Hornet e Scruff), que também apresentaram como resultados o pouco uso em Confresa e cidades vizinhas. É possível que outras formas de homossociabilidade existam na região mesmo que de forma velada e/ou nunca enunciada ${ }^{9}$, como a que ocorria na área rural do Ceará, conforme descrita por Ferreira (2006), época anterior aos aplicativos - ou que os indivíduos não heterossexuais conscientes de sua orientação migrem para cidades maiores.

Nos cem perfis mais próximos contados a partir do centro de Confresa, houve um percentual de 21,4\% (3 em 14) que mostrava o rosto claramente. É um percentual abaixo ao da capital do Estado, na qual mais de $33 \%$ mostra o rosto claramente. Como já mencionado anteriormente, isso está provavelmente relacionado à pressão heteronormativa que tende a ser menor nas grandes cidades e maior em cidades pequenas.

Em relação às idades relatadas abertamente nos perfis dos usuários, cerca de metade era de jovens até 25 anos. Uma hipótese plausível para explicar essa característica pode ter a ver com uma lógica geracional, de uma juventude mais afeita à tecnologia e que foi socializada em um momento histórico em que novelas e seriados tinham mais personagens gays com os quais eles podiam se identificar. No entanto, essa questão da idade deve ser observada com cuidado, porque não é incomum que a verdadeira idade não seja exposta em aplicativos de namoro.

Sobre a autoidentificação étnico-racial, entre os que declaravam essa característica, pouco mais da metade (8 em 14) declarou-se negra. Em outras características fenotípicas (altura e peso), havia uma miscelânea de variedades de perfis, assim como as de preferências sexuais (ativo, passivo, versátil e gouinage), que a priori não parecem ter relevância ou cuja comparação com outras regiões não parecem agregar muito a pesquisa.

Em nenhum dos cem perfis mais próximos foi encontrada a autodeclaração de soropositividade $(\mathrm{HIV+)}$. Isso pode significar que: (1) não há usuários do aplicativo soropositivos na região; (2) os usuários não conhecem o seu status sorológico; (3) os usuários soropositivos preferem ocultar a sua situação. Na pesquisa de Kerr et al (2018), 18,4\% dos homens que fazem sexo com outros homens no Brasil são soropositivos para o HIV, sendo que esse número atinge $25 \%$ em algumas regiões, como em São Paulo - SP. É válido salientar que essa omissão do status sorológico não é uma característica específica de Confresa e região, mas

Ferreira (2006) narra que, na área rural do Estado do Ceará, a homossociabilidade ocorre de forma velada em paralelo com uma pseudoheterossociabilidade pública, isto é, os homens agem publicamente como amigos heterossexuais - alguns casados com mulheres -, mas que se aventuram sexualmente com outros homens. Nessas relações microssociais, o silêncio sobre o assunto e a dissimulação são as regras de ouro. 
generalizada no Brasil. Isso significa que a hipótese 3 - de sorofobia, estigmatização de soropositivos e/ou tabus em torno do HIV - é a mais forte, embora possa estar combinada com a hipótese 2 .

\section{Considerações Finais}

Nessa pesquisa, identificou-se um número total baixo de usuários do aplicativo Grindr na cidade de Confresa - MT e região, especialmente dos moradores locais. Vários fatores podem explicar essa baixa popularidade nessa região como o desconhecimento do aplicativo e o medo de ter sua orientação exposta. Isso não significa que não haja minorias sexuais na região, mas que elas provavelmente têm outra forma de homossociabilidade ou buscam se conformar a formas de sociabilidade heteronormativadas. Para verificar essas hipóteses, outra pesquisa com entrevistas em profundidade seria necessária.

A homossociabilidade, ao pressupor que seus participantes se reconheçam de alguma maneira como minorias sexuais, é uma forma de resistência à heteronormatividade. Nesse sentido, a ausência ou escassez da homossociabilidade pode ser sintomática de contextos sociais em que a homossexualidade, a bissexualidade e a transexualidade ainda são considerados tabus.

\section{Referências Bibliográficas}

BECKER, Howard. Outsiders: estudos de sociologia do desvio. Rio de Janeiro: Zahar, 2008.

BUTLER, Judith. Gender Trouble: feminism and the subversion of identity. Routledge, 1990.

BLACKWELL, Courtney; BIRNHOLTZ, Jeremy; ABBOTT, Charles. Seeing and being seen: co-situation and impression formation using Grindr, a location-aware gay dating app. New Media \& Society, v. 17, n. 7, p. 1117-1136, 2015.

BRUBAKER, J. R.; ANNANY, M.; CRAWFORD, K. Departing Glances: a sociotechnical acount of 'leaving Grindr'. New Media \& Society, v. 18, n. 3, p 373-390, 2016.

COLLING, Leandro. Stonewall +40 o que no Brasil? EdUFBA, 2011.

FERREIRA, Paulo R. S. Os Afectos Mal-Ditos: o indizível sobre as sexualidades camponesas. Dissertação (Mestrado em Antropologia). Universidade de Brasília, 2006.

GIL, Antônio Carlos. Pesquisa Social. São Paulo: Atlas, 1999.

IBGE. Estimativa Populacional dos Municípios Brasileiros. Rio de Janeiro, 2018. Acessado em 10/02/2020, disponível em: 
$<$ https://www.ibge.gov.br/estatisticas/sociais/populacao/9103-estimativas-depopulacao.html?edicao $=22367 \& \mathrm{t}=$ resultados $>$.

KERR, Lígia et al. HIV Prevalence Among Men Who Have Sex With Men in Brazil: results of the 2nd national survey using respondent-driven sampling. Medicine, may/2018, vol. 97, issue $1 \mathrm{~S}, \mathrm{p} . \mathrm{S} 9-\mathrm{S} 15,2018$.

LANZARINI, Ricardo; RIAL, Carmen. Turismo gay na ilha de Santa Catarina: homossociabilidades e perspectivas. Anais do $9^{\circ}$ Seminário Internacional Fazendo Gênero: diásporas, diversidades e deslocamentos, 2010.

MORENO, Gislaene; HIGA, Tereza Cristina Souza. Geografia de Mato Grosso: território, sociedade e ambiente. $2^{\mathrm{a}}$ ed. rev. Cuiabá: Entrelinhas, 2017.

MISKOLCI, Richard. A Teoria Queer e a Sociologia: o desafio de uma analítica da normalização. Sociologias, Porto Alegre, ano 11, nº 21, p.150 - 182, jan./jun. 2009.

RICE, Eric et al. Sex Risk Among Young Men Who Have Sex With Men Who Use Grindr, a smartphone geosocial networking application. Journal of AIDS and Clinical Research, $n$. supplement 4, 2012.

RICH, Adrienne C. Reflections on 'Compulsory Heterosexuality'. Journal of Women's History, vol. 16, n 1, p. 9-11, 2004.

RIOS, Luis Felipe. Corpos e Prazeres nos Circuitos de Homossociabilidade Masculina do Centro do Rio de Janeiro. Ciência \& Saúde Coletiva, v. 13, n. 2, p. 465-475, 2008.

TANNUS, Ana M. N. Amor em Tempos de Banda Larga: uma análise sociológica do aplicativo Tinder. Trabalho de Conclusão de Curso (Graduação em Ciências Sociais). UNIFESP. Guarulhos - SP, 2018.

WARNER, Michael. Introduction: fear of a queer planet. Social Text (Special Edition), p. 317, 1991. 